\title{
Introduction to the History of Pathology series
}

\author{
Jan G. van den Tweel • Clive R. Taylor
}

Received: 17 April 2010 /Accepted: 19 April 2010/Published online: 20 May 2010

(C) The Author(s) 2010. This article is published with open access at Springerlink.com

"History is the essence of innumerable biographies." Thomas Carlyle; 1795-1881

The History of Medicine is a flourishing field of interest and research, with an extensive literature and several notable books, including some in the "popular" press. Interest in the History of Pathology per se is far less evident. While admitting to bias, we are of the opinion that Pathology receives short shrift in general medical histories, an opinion that we believe is shared by many colleagues. Certainly there are many pathologists who are interested in specific historical aspects of their profession. However, there are few national or international societies concerning the history of pathology. Until recently, there was no such group in Europe, a deficiency now being remedied by the formation of a History of Pathology Working Group of the European Society of Pathology. The History of Pathology Society in America has a longer record, sponsoring a 2-h "companion meeting" at the annual United States and Canada Academy of Pathology (USCAP) meeting, but it is far from active during the remainder of the year. "Unknown Unloved" is probably the best way to describe the present situation.

J. G. van den Tweel $(\bowtie)$

Department of Pathology H4.312, University Medical Center,

Heidelberglaan 100,

3584 CX Utrecht, The Netherlands

e-mail: j.vandentweel@umcutrecht.nl

C. R. Taylor

Department of Pathology, HMR 311, Keck School of Medicine of the University of Southern California,

2011, Zonal Avenue,

Los Angeles, CA 90033, USA

e-mail: cltaylor@usc.edu
The "Companion Meeting" at the USCAP in 2008, in Denver, CO, USA, was advertised under the billing of "Famous Europeans who shaped Pathology." It drew an audience exceeding the meeting room capacity. The positive reactions of that audience stimulated subsequent initiatives to organize History of Pathology Symposia at the International Academy of Pathology Congress in Athens in 2008 and at the European Society of Pathology Congress of 2009. Both were well attended, providing food for thought and encouragement for the notion of soliciting a series of papers in this area or a small book, or as it turns out, both. Previous books have been few. Most enduring among these was the comprehensive $A$ History of Pathology written by Esmond R. Long. Initially, published in 1928, a second updated Dover edition appeared in 1964. Contact with the present owners of Dover publications revealed no interest for a new edition. Fortunately Virchows Archiv was of a different opinion. The Editors have committed ample space over the next 2 years for a series of articles about the different aspects of our history. At the end of the series, the manuscripts will be combined into a book. We are very grateful to Professors H. Höfler, Editor-in-Chief, and F.T. Bosman, managing editor of Virchows Archiv, for their enthusiastic support of this project.

Although the different topics will cover the time span from antiquity to the present, the papers will not be published in chronologic order. However, because each paper is designed to stand alone, this should cause no problems. The first paper in the series appears in this issue of Virchows Archiv and provides an overview of the whole period, highlighting some of the key historical moments that have determined the shape of current pathology practice. Forthcoming articles will deal with particular historical periods (e.g., the Antiquities, the Roman influence, 
the Arab influence), with groups of important scientists (e.g., famous anatomists - you use their names daily), or with remarkable individuals, who made special contributions, and were in many ways "early pathologists." In addition, there will be selected articles on the history of various technical and educational aspects, such as microscopy, stains and staining methods and on the founding of museums. The twentieth century will mainly be illustrated through the history of classifications of diseases. We fully realize that it is absolutely impossible adequately to cover, or even mention, everyone who has made contributions in the field, neither is it possible to cover every discovery of significance.

A coinciding relevant event is the production of an Encyclopedia of Pathology, to be published in 2012, also by Springer Verlag. This encyclopedia has a subsection on the History of Pathology and will carry more than 150 entries on historical persons and events. Both projects will be closely integrated.

We hope that these publications in Virchows Archiv, and also in the Encyclopedia, will raise the level of interest in the fascinating history of our specialty and will lead to more research and critical thought concerning what we do as pathologists and why and how we do it.

Guest Editors

Open Access This article is distributed under the terms of the Creative Commons Attribution Noncommercial License which permits any noncommercial use, distribution, and reproduction in any medium, provided the original author(s) and source are credited. 